\title{
A new leptomitid-like sponge from the Early Ordovician of China with heteractinid spicules
}

\author{
JOSEPH P. BOTTING \& ZHANG YUANDONG
}

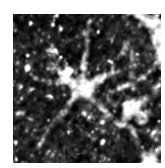

\begin{abstract}
A new sponge, Heteractenigma yui gen. et sp. nov., is described from the Corymbograptus deflexus Biozone (Floian) of the Ningkuo Formation in western Zhejiang Province, China. The tall, thin-walled species possessed unique features including a combination of robust longitudinal monaxons, fine sub-transverse monaxons, and minute hexactine and heteractine body wall spicules. The heteractine spicules have five rays in one plane, and closely resemble those of the problematic Burgess Shale sponge Petaloptyon danei. The monaxon organisation and body form, in contrast, accord with those of leptomitids. Although it is not currently possible to establish the precise relationships of this species, due to the major differences from other known taxa, it includes features characteristic of heteractinids, reticulosans and leptomitid protomonaxonids. This may indicate that the species belongs to the stem-group of either Porifera or Silicea. The unique architecture of the species also confirms that there remain large gaps in our knowledge of early sponges, even at high taxonomic level. $\bullet$ Key words: Porifera, Floian, stem-group, phylogeny, Heteractinida, Leptomitidae, Silicea.
\end{abstract}

BotTing, J.P. \& ZHANG, Y.D. 201X. A new leptomitid-like sponge from the Early Ordovician of China with heteractinid spicules. Bulletin of Geosciences 88(1), 207-217 (4 figures). Czech Geological Survey, Prague. ISSN 1214-1119. Manuscript received April 18, 2012; accepted in revised form November 1, 2012; published online December 5, 2012; issued December 6, 2012.

Joseph P. Botting (corresponding author) \& Zhang Yuandong, State Key Laboratory of Palaeobiology and Stratigraphy, Nanjing Institute of Geology and Palaeontology, 39 East Beijing Road, Nanjing 210008, China; acutipuerilis@yahoo.co.uk,ydzhang@nigpas.ac.cn

The Leptomitidae (De Laubenfels 1955, Finks \& Rigby 2004a) are a group of protomonaxonid sponges that are typical of the Cambrian Burgess Shale-type faunas. The included genera show an overall arrangement of coarse longitudinal monaxons with finer transverse monaxons, in most taxa bundled to create a semi-reticulate array that resembles that of the hexactinellid-like Reticulosa (Debrenne \& Reitner 2001). The group is often regarded as falling into the demosponge stem group (Rigby \& Collins 2004), and is widespread through the early and middle Cambrian (e.g. Chen et al. 1989, Rigby \& Hou 1995, García-Bellido Capdevilla 2003, Rigby \& Collins 2004).

In contrast, the Heteractinida are a group of primarily Early Palaeozoic sponges that are traditionally regarded as primitive calcareans (Reid 1967, Mehl \& Reitner 1996), or as a separate class (Finks \& Rigby 2004b). They are characterised by multi-rayed (typically hexaradiate, sometimes also with proximal and distal rays), at least partly calcitic spicules, which are in the best-known taxa (Astraeospongiidae) densely intergrown and cemented by secondary calcareous deposits to form a relatively rigid architecture. These sponges are occasional but widespread members of Silurian and Devonian carbonate platform communities. The robust spicules are in some cases well preserved, and reveal a relatively complex structure including a structurally (but not mineralogically) distinct axial core (Mehl \& Reitner 1996), and the groups is widely accepted as being at least close to early-branching groups of the modern Calcarea such as the Pharetronida. The Astraeospongiidae are morphologically and structurally conservative, the majority being bowl-shaped to saucershaped.

The earliest and simplest heteractinids are the Eiffeliidae, which are characterised by unfused, relatively slender spicules in a thin wall (Finks \& Rigby 2004b). They are best known from the Cambrian Eiffelia Walcott, 1920, but the related (although thicker-walled) Wewokellidae continued until at least the Permian (Rigby et al. 2005). The forms previously described generally fall easily into the relatively simple phylogeny first proposed by Rietschel (1968) and Rigby \& Nitecki (1975), but still accepted in broadly the same form today (Finks et al. 2004); the main exception is that of chancelloriids, whose affinities remain uncertain. This phylogeny provides a 
simple framework, with thick-walled, robust construction evolving several times from a thin-walled ancestral condition resembling the structure of Eiffelia.

Perhaps surprisingly, the early, thin-walled and globose taxa show the most problematic features. The Burgess Shale sponge Eiffelia globosa has been shown to possess morphological features supposedly diagnostic of hexactinellid sponges (Botting \& Butterfield 2005), and also appears to have biminerallic (silica and calcite) spicule construction (Botting \& Butterfield 2005, Bengtson \& Vinther 2006). These features suggest that both calcarean and silicean spicules evolved from biminerallic precursors, especially as biminerallic spicules have since been confirmed in the morphologically very different protomonaxonid Lenica (Botting et al. 2012). Relevant unusual features of other taxa assigned to the Eiffeliidae are discussed below.

The description of biminerallic spicules in early and probably stem-group sponges (Botting et al. 2012), combined with an increasing range of architectures and spicule forms in Cambrian taxa, has led to uncertainty over the affiliation of previously unproblematic sponge fossils. Reticulosan sponges, for example, have previously been regarded as hexactinellids, but the presence of hexactinellid-like spicules in Eiffelia (Botting \& Butterfield 2005) implies that they are equally likely to be stem-group Silicea as stem-group Hexactinellida. Similarly, at least some Protomonaxonida (Finks \& Rigby 2004a) may be partly stem-group Silicea or stem-group sponges (Botting et al. 2012) rather than basal demosponges. The Heteractinida appear to include forms close to the common ancestor of Calcarea and Silicea (Botting \& Butterfield 2005; but see also Harvey 2010), rather than being clearly on the calcarean lineage, and the group may be paraphyletic with respect to the extant classes. Problematic heteractinid-like taxa such as Petaloptyon and the polyactinellids (known only from isolated spicules; summarised by Finks \& Rigby 2004c) need to be carefully reconsidered with respect to possible alternative interpretations of their phylogenetic position. Unfortunately, critical aspects such as spicule mineralogy are often difficult to establish in early sponge fossils, and the limited record makes many morphological analyses speculative. New taxa with previously unknown combinations of features are critical to confirming or refuting suggested evolutionary scenarios.

In this paper we describe a new heteractine-bearing sponge with several features unique to the Leptomitidae. The subcylindical body form is previously unknown in heteractinids, and the spiculation contains large longitudinal monaxons resembling those of leptomitids, with minute tetraradial and pentaradial wall spicules that resemble most closely those of Petaloptyon. The combination of features described indicates a large unknown diversity of early sponges with heteractinid-like features, and supports the notion that the Heteractinida include taxa in the poriferan stem-group.

\section{Geological setting and material}

The Ordovician rocks of South China occupy three principal regions based on depositional regimes (Zhang et al. 2010; Fig. 1A): (1) Yangtze Region (Platform) situated in the northwest of South China, which is dominantly carbonate or a mixture of carbonates and siliciclastics (e.g. green-yellow shale), and with both shelly fossils and plankton; (2) Jiangnan Region (Slope), a narrow belt oriented northeast-southwest, extending to the southeast of the Yangtze Region, and typified by black shale with some carbonate layers; the biota is dominated by planktonic fossils, including graptolites, acritarchs, and chitinozoans, with a few deep-water shelly fossils; (3) Zhujiang Region (Basin), situated in the southeast of South China, dominated by black shale and chert, and preserving predominantly planktonic organisms, especially graptolites.

The Liujia section, where our sponges were found, belongs to the eastern part of the Jiangnan Region, and is located near Liujia village, Hecun Township, Tonglu County, western Zhejiang Province. In the western part of Zhejiang, the Early to Middle Ordovician rocks are generally divided into three northeast- to southwest-trending belts separated by three tectonic faults that may have been active since Sinian (Ediacaran) times (Yu 1996, Zhang et al. 2007, Rong et al. 2010). These belts are: (1) Northwest belt (from the southeast margin of Yangtze Platform to the Majin-Wuzhen Fault), characterized by the deposition of siliciclastics in the Early to Middle Ordovician, and part of the so-called Zhe-Wan (Zhejiang and Anhui Provinces) Basin; (2) Central Belt (from the Majin-Wuzhen Fault to Qiuchuan-Xiaoshan Fault), predominantly shale and fine sandstones from the Early to Middle Ordovician; includes the Liujia section; (3) Southeast Belt (from QiuchuanXiaoshan Fault to Jiangshan-Shaoxing Fault), typified by intercalations of shale and carbonates, with benthic assemblages are assigned to BA4 to BA5. Further eastwards, beyond the Jiangshan-Shaoxing Fault, is a poorly-known area covered by thick Mesozoic deposits, corresponding to the Cathaysian land as proposed by Grabau (1924).

The sponges are from horizon AEP-LJ 6-0 of the Ningkuo Formation, in the Liujia section, and are associated with many graptolites including Phyllograptus typus, Pseudophyllograptus angustifolius, Tetragraptus serra, Expansograptus extensus, etc. (Fig. 1B; for a complete list of the graptolites from the section, see Zhang et al. in press). Some specimens of Corymbograptus cf. deflexus occur a few meters below the sponge horizon, and Azygograptus suecicus first appears a few meters higher. The graptolite fauna indicates an age corresponding to the Corymbograptus deflexus 
Figure 1. Location map and partial range chart of taxa within the type section, showing the horizon and age of the sponges. A - location of the Liujia section in western Zhejiang Province, South China. Abbreviations: JS - Jiangnan Slope; NC - North China; SC - South China; YP - Yangtze Platform; ZB - Zhujiang Basin. $\bullet B$ - range chart of Floian and Dapingian fossils from the Liujia section, indicating associated fauna and stratigraphic context of the new sponge. Arrowed ranges indicate that the taxa extend their ranges beyond the section illustrated.

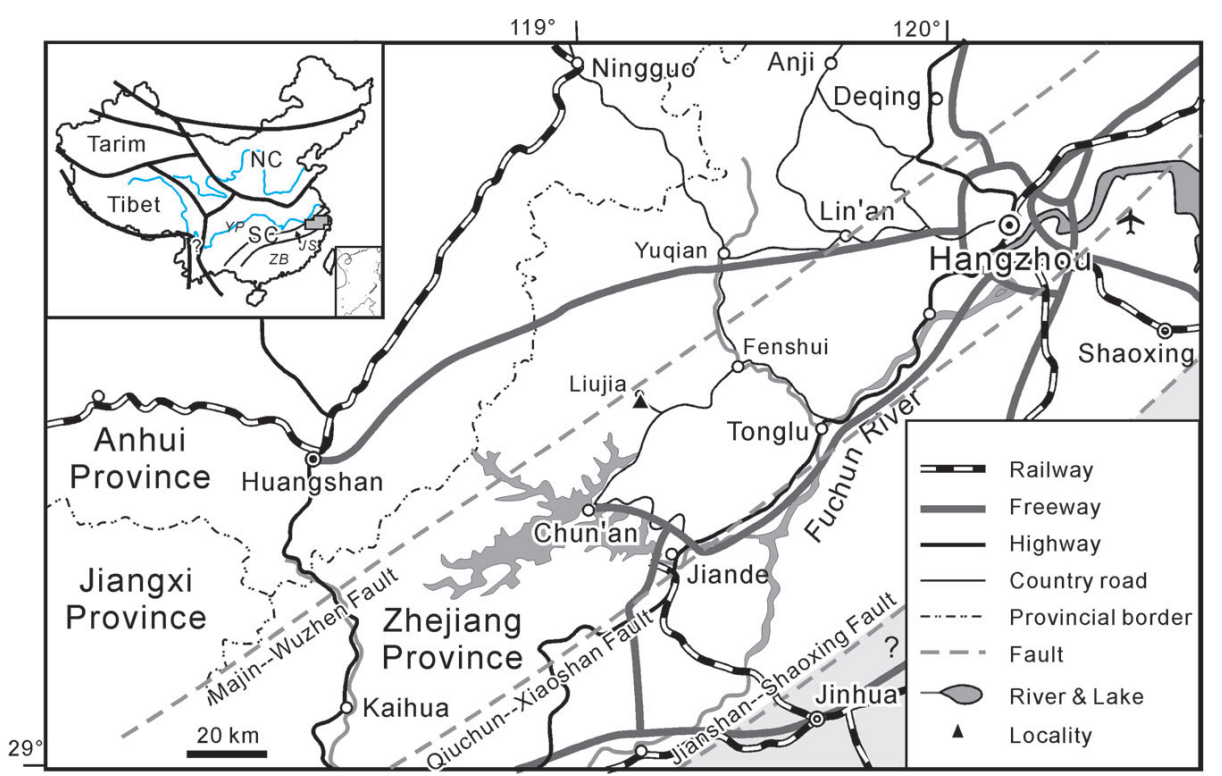

A

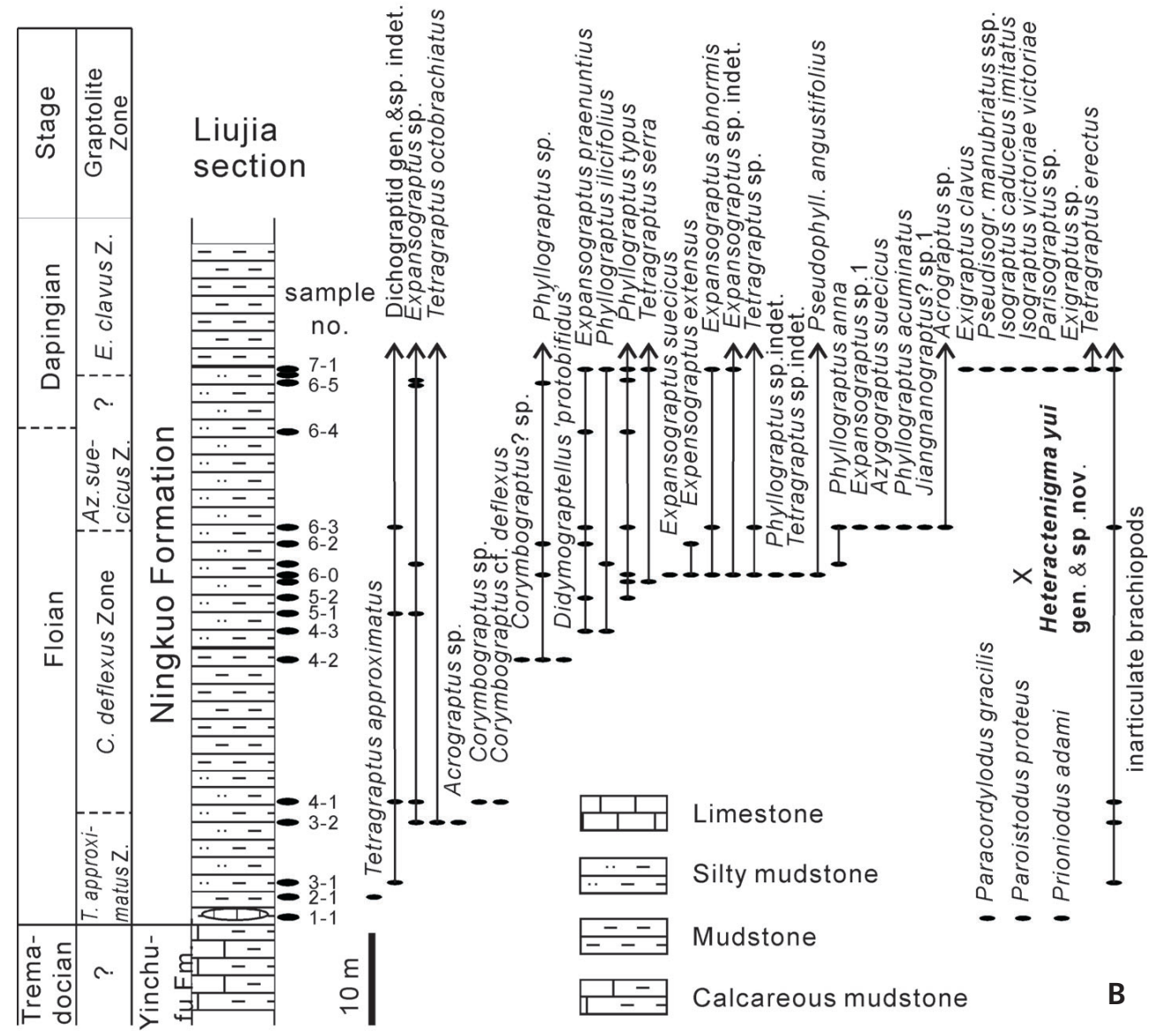

Zone of the late Floian Stage, which is correlated to the lower part of Didymograptus simulans Zone in Great Britain. Some forty meters below the horizon yielding sponges, the graptolite Tetragraptus approximatus was found, and a conodont fauna was identified, including Paracordylodus gracilis, Paroistodus proteus and Prioniodus adami, both suggesting an age of earliest Floian. Some inarticulate brachiopods, such as Palaeoglossa, occurred intermittently through the sampled interval containing the sponges.

The sponge specimens were collected by a senior geologist from the Zhejiang Institute of Geological Survey, Mr. Yu Guohua, in 2009 when he collected the section (with 
several colleagues) for graptolites as part of his mapping work. A search for additional specimens by Zhang Yuandong failed to recover any further material, implying that the sponge is either rare, or restricted to precise horizons.

\section{Systematic palaeontology}

Terminology for spicules is as follows: hexactine: six orthogonal rays; stauract: four orthogonal rays in one plane; triradiate: three rays in one plane, with or without perpendicular rays; heteractine: five (pentaradiate) or six (hexaradiate) rays in one plane, with or without perpendicular rays. All specimens of the new sponges are housed in the Nanjing Institute of Geology and Palaeontology, Nanjing, China, with specimen numbers NIGP154824-154827. Some of the comparative material referred to in text and figures is housed in the Royal Ontario Museum, Canada (ROM).

Phylum Porifera Grant, 1836

Class, Order, Family uncertain

\section{Genus Heteractenigma gen. nov.}

Type species. - H. yui sp. nov.

Etymology. - Referring to the enigmatic phylogenetic relationships of this heteractinid-like sponge. Gender $f$.

Diagnosis. - Tall subcylindrical sponge with skeleton composed of large, spaced, longitudinal monaxons and sparse, fine, transverse monaxons, with dense array of minute stauractine (or hexactine) and heteractine (mostly pentaradiate) spicules, locally in regular diagonal mesh; monaxons converge slightly around osculum to produce dense fringe of marginalia.

Description. - See species description of $H$. yui sp. nov., below.

Remarks. - The new genus is unlike all described taxa in skeletal architecture and spiculation, and represents a previously unknown group. The possible relationships of the sponge are discussed below, based on individual characteristics shared with other early sponges.

\section{Heteractenigma yui sp. nov.} Figures 2, 3

Holotype. - NIGP154824, complete specimen, well preserved flattened skeleton with iron oxide spicule replacements; no counterpart.

Paratypes. - NIGP154825-6, two partial specimens on the holotype slab, one partially disarticulated. NIGP154827, additional partial specimen on separate block. No counterparts. An additional small fragment is present on the slab with NIGP154827.

Material. - No further specimens are currently known.

Type horizon and locality. - Corymbograptus deflexus Biozone (Floian, Ordovician) of the Ningkuo Formation; Liujia section, Tonglu Country, western Zhejiang Province, China.

Etymology. - After Mr. Yu Guohua of the Zhejiang Institute of Geological Survey, who discovered the specimens.

Diagnosis. - As for genus.

Description. - Tall conical (subcylindrical) sponge, the holotype (Fig. 2A, C, D) $50 \mathrm{~mm}$ long and $8.5 \mathrm{~mm}$ wide at maximum width, reached approximately $10 \mathrm{~mm}$ from upper margin. No other specimens are complete; the largest specimen is broken at $44 \mathrm{~mm}$ from the base, but at that point is $11 \mathrm{~mm}$ wide. The base is rounded, narrowing abruptly in the basal $5 \mathrm{~mm}$ from more than half of the maximum diameter (Fig. 2C, E), but the rate of narrowing varies between specimens. The osculum of the holotype is slightly narrowed, with outer diameter around $6 \mathrm{~mm}$ but curving inwards sharply at extreme apex; inner diameter difficult to measure but close to $5 \mathrm{~mm}$, implying the original wall thickness at the oscular margin was a maximum of $0.5 \mathrm{~mm}$, and probably less (Fig. 2D). One partly disarticulated specimen (NIGP154826; Fig. 2F) shows irregular mineralisation of the body wall, which in lateral cross-section is consistently 0.25-0.30 mm thick.

All spicules are replaced by weathered aluminosilicates and iron oxides (determined by SEM-mounted EDX), and all except the most three-dimensional large monaxons are virtually invisible in SEM (including backscattered electron mode). The skeleton is composed of

Figure 2. Heteractenigma yui gen. et sp. nov., light macro-photographs. - A - overall view of holotype slab, showing holotype NIGP154824 (1), paratype NIGP154825 (2) and disarticulating paratype NIGP154826 (3) • B - overall view of secondary slab, showing paratype NIGP154827 and a small additional fragment. $\bullet \mathrm{C}$ - complete view of holotype, NIGP154824. $\bullet$ D - apical region of holotype. $\bullet$ E - basal region of NIGP154825. $\bullet$ F - overall view of disarticulating paratype NIGP154826, with upper edge preserving margin of sponge with consistent thickness of mineralisation. Scale bars: A-C $-10 \mathrm{~mm}$; D-F $-5 \mathrm{~mm}$. 

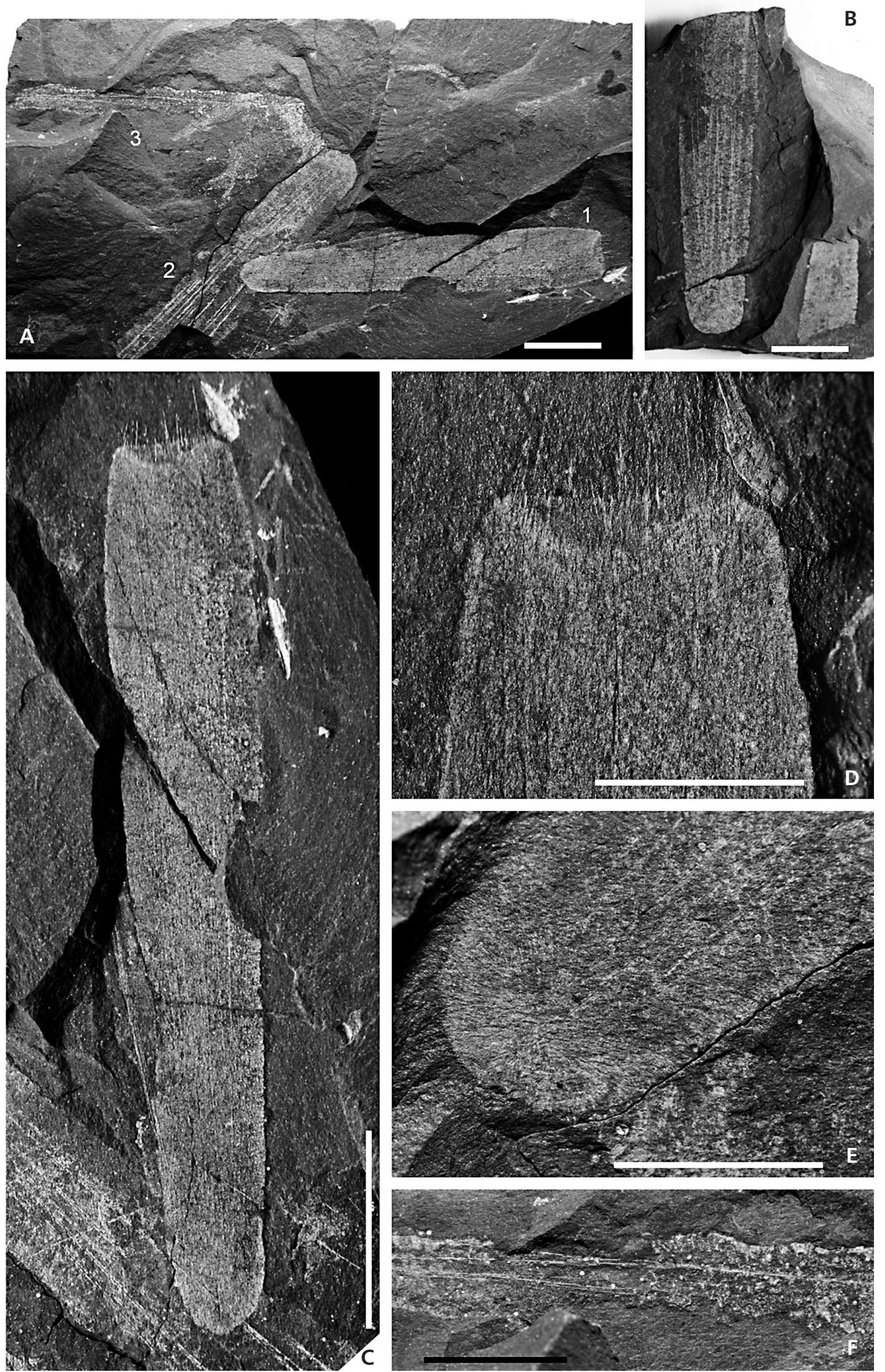
three main elements: longitudinal monaxons, fine transverse monaxons, and an irregular mesh of minute stauractines and pentaradiates, with rare triradiate spicules (see below). A few examples of possible hexaradiates are also present, but none could be confirmed. The large, longitudinal monaxons (Figs 2, 3E) are up to at least $40 \mathrm{~mm}$ long and $0.1 \mathrm{~mm}$ wide in the holotype, the longest running for over half of the length of the sponge. No spicules appear to continue from the base to project as marginalia, however; marginalia initiate at least $10 \mathrm{~mm}$ above the base, and usually more. Individual monaxons sometimes overlap precisely to form en echelon lines (Fig. 3E), but are usually isolated. Spicules are oxeas where terminations can be observed: distal tips of marginalia are sharply pointed, and in NIGP154825 some acute proximal tips are also visible.

Multi-rayed body wall spicules (Fig. 3A-C) are minute, and dominantly composed of four subequal rays in one plane. Despite their small size and mineralogically modified condition, many show a dark spot in the centre of the junction, indicating projecting rays or bosses and suggesting originally hexactine symmetry. The axial structure could not be resolved in detail (spicules are obscure in SEM due to replacement by material similar to the matrix), but could indicate either an axial canal or a central core of a different mineralogy, such as the silica core of calcareous spicules known from some heteractinids and protomonaxonids (Bengtson \& Vinther 2006, Botting et al. 2012). Spicules occur in several sizes within an individual, but maximum observed ray length is $0.2 \mathrm{~mm}$, with diameter $0.01-0.02 \mathrm{~mm}$. Most spicules have ray lengths $0.05-0.1 \mathrm{~mm}$ and diameter approximately one-tenth of ray length. There does not appear to be a regular ordering of sizes, and little organisation of sizes within the body wall, although the holotype appears to have a higher proportion of larger spicules in the basal region that the apical region. The same dimensions and distributions are seen in the other available specimens, suggesting that the largest observed spicules had reached a maximum size.

In all specimens, a small number of five-rayed spicules are visible, but numbers vary considerably; the largest number is seen in a disarticulating specimen (NIPG154826; Fig. 3B). These spicules differ from the tetraradial spicules only in the number of rays, which are evenly spaced, generally straight and subequal in length. As with hexactines, there is evidence in some cases for a distal or gastral ray in the form of an axial structure in cross-section. A few triradiate spicules (Fig. 3C) are also present.

Spicules are superficially disorganised and in some regions show no preferred orientation, but in other areas reveal a clear diagonal mesh (Fig. 3A). Where present, the orientations is irregular, but typically $20-30^{\circ}$ to the horizontal. Spicule alignment is most obvious in basal
(Fig. 3D) and apical (Fig. 2D) regions. In the uppermost $0.8 \mathrm{~mm}$ of the holotype, hexactines are longitudinally aligned, and arranged to form continuous spicule strands from overlapping and touching ray tips. This is combined with intercalation of an array of either fine monaxons or highly elongated spicule rays to form a dense marginalial fringe up to $1 \mathrm{~mm}$ long (Fig. 2D). Interspersed with these are more robust projecting tips of the coarse longitudinal monaxons, which extend up to $4 \mathrm{~mm}$ beyond the apex of the body wall.

The basal part of the sponge shows similar alignment of hexactines and fine monaxons, best preserved in NIGP154825 (Fig. 3D) where oblique compression has exposed the basal radiation centre. Spicules form a relatively regular, fine longitudinal-transverse grid that loses coherence between 2 and $3 \mathrm{~mm}$ from the nucleation centre, apparently coinciding with the area that contains fine monaxons. The holotype exposes the wrong surface in the basal region, but despite heavy mineralisation, a trace of the regular radiating grid is visible in NIGP154827 (Fig. 2B).

Specimen NIGP154827 shows a small number of fine, dominantly transversely-oriented monaxons up to $1 \mathrm{~mm}$ long but only $0.02 \mathrm{~mm}$ in diameter (Fig. 3F, G). These spicules are often in parallel clusters of two or three spicules, although other examples occur singly, and often obliquely (Fig. 3F). One oblique cluster of fine monaxons has also been seen. These transverse spicules have not been observed in the other specimens, although monaxons with similar proportions are present in the basal region (discussed above).

Remarks. - There are no sponges that are easily confused with the new species, even as partial specimens. The combination of body form and spiculation is currently entirely unique, although there is surprising variation in architecture. The transverse monaxons are an important component of the skeleton, but have not been observed in all specimens. The regularity of the pseudo-diagonal grid of hexactines varies substantially between specimens, as does the proportion of pentaradial spicules. It is possible that two closely related species are represented by the material, but at present the variation appears to form a continuum, and is treated as such.

Occurrence. - Known only from the type locality.

\section{Discussion}

Heteractenigma falls into a growing number of Cambrian-Silurian hexactinellid-like sponges (e.g. Botting 2004, Wu et al. 2005, Botting \& Rhebergen 2011, Botting et al. in press b) that are difficult to assign to previously 

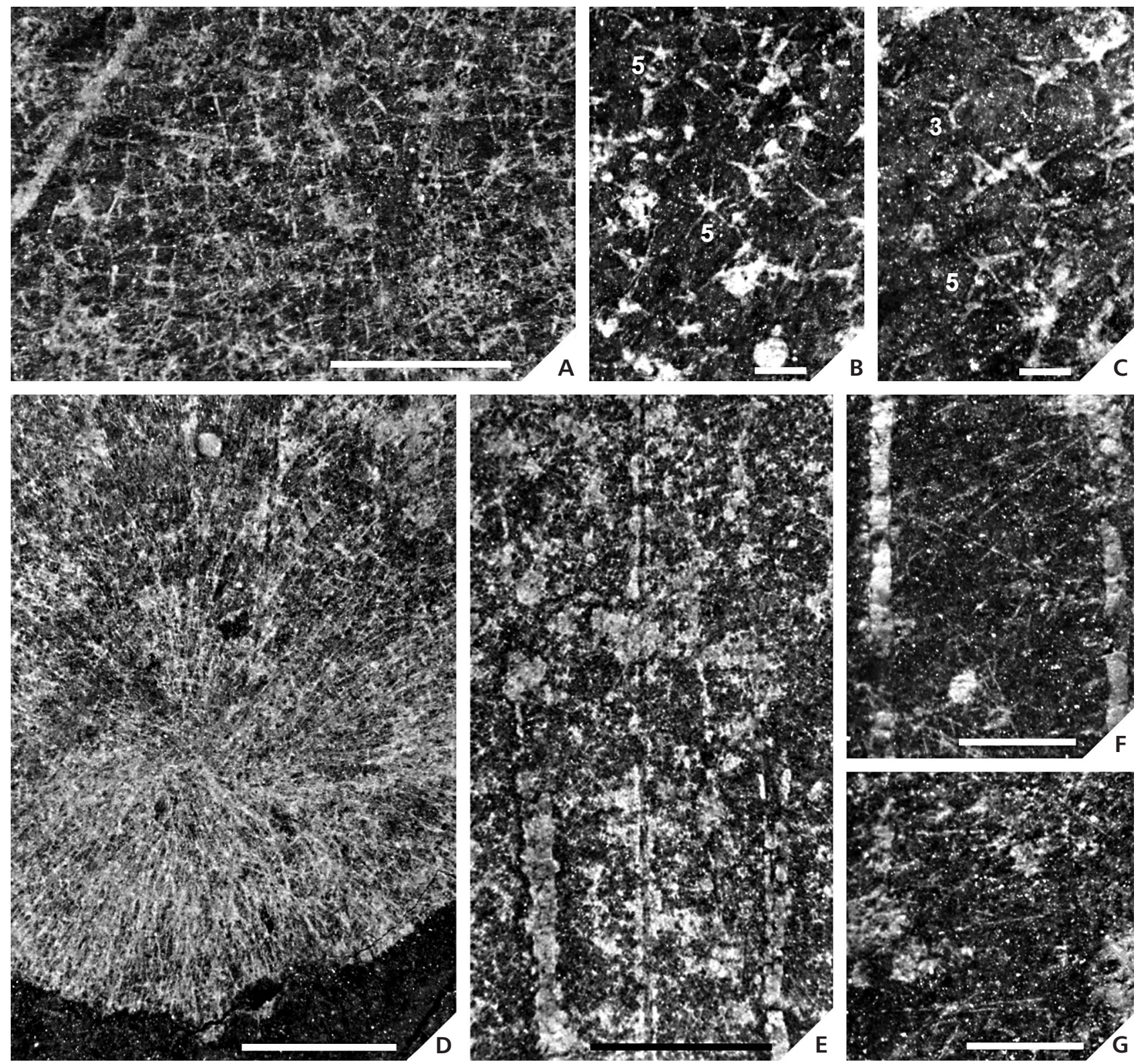

Figure 3. Heteractenigma yui gen. et sp. nov., photomicrographs, showing details of skeletal architecture. $\bullet$ A - detail of paratype NIGP154825, showing semi-regular orientation of minute hexactine-like spicules into a local square grid. $\bullet$ B - detail of disarticulating paratype NIGP154826, showing examples of five-rayed spicules (5). $\bullet \mathrm{C}$ - detail of NIGP154826 showing triradiate (3) spicule in addition to pentaradiate (5) spicules and hexactine-like spicules. $\bullet$ D - base of NIGP154825, showing skeletal radiative centre and lines of aligned hexactines and possible fine monaxons. $\bullet$ E-G - details of paratype NIGP154827; E - showing clustered longitudinal monaxons; F - loose fine monaxons in oblique orientations, between robust longitudinal monaxons; $\mathrm{G}$ - isolated and clustered transverse fine monaxons, with much smaller hexactine-like spicules. Scale bars: A, D - $1 \mathrm{~mm}$; B, C - $0.1 \mathrm{~mm}$; $\mathrm{D}-\mathrm{G}-0.5 \mathrm{~mm}$

known groups, or to place into a phylogenetic framework. The continued discovery of new, morphologically unique taxa also implies that the known record is very incomplete even at family level. However, many of the difficulties in interpretation may be resolved as a result of changing perspectives on the nature of poriferan stem groups and the affinities of major Palaeozoic groups such as the reticulosans and protomonaxonids. The recognition of biminerallic spi- cules in Lenica (Botting et al. 2012) shows that at least some protomonaxonids branched before crown-group Silicea, but it remains unclear whether they represent stem-group Silicea, or a more basal lineage. The presence of hexactinellid-like spicules in Eiffelia (interpreted as close to the common ancestor of Silicea and Calcarea; Botting \& Butterfield 2005), another sponge with preserved biminerallic spicules (Bengtson \& Vinther 2006), implies 
that these spicules were present at least within the stem group of Silicea, and probably also in stem-group Calcarea + Homoscleromorpha, and stem-group Porifera. Unexpected distributions of spicular characters previously thought to be diagnostic of only one class is confirmed by the presence of robust organic sheaths in isolated hexactines from the Forteau Formation (Harvey 2010), a feature effectively limited to Calcarea among extant sponges. Determining the precise phylogenetic position of early, superficially hexactinellid-like sponges is therefore much more complex than has been appreciated.

Heteractinids have until now been regarded as relatively conservative (Rigby \& Nitecki 1975, Finks et al. 2004) in architecture and structure. Although de Laubenfels (1955) included a variety of disparate taxa (and assigned them all to the Hyalospongea, equivalent to Hexactinellida), his view has not been followed recently. The chancelloriids in particular are now regarded as a separate group, of uncertain relationships, and perhaps not even sponges (e.g. Bengtson \& Hou 2001). The most problematic taxon currently included in the Heteractinida is Petaloptyon Raymond, 1931 (see also Rigby \& Collins 2004), also described under the name Canistrumella (Rigby 1986), but the problems interpreting its relationships have been largely overlooked. Finks \& Rigby (2004b) followed Rigby \& Collins (2004) and included it in the Eiffeliidae, but the differences in spiculation and architecture makes this assignment untenable. Petaloptyon possessed a stalked globose body with the thin wall divided into vertical panels with and without structural gaps, and the spicules were minute and dominantly pentaradial (Fig. 4D) in contrast to the large hexaradial spicules of other eiffeliids. The mineralogy of its spicules is unconfirmed, and the phylogenetic position of Petaloptyon remains unknown.

The other somewhat aberrant early heteractinid is Eiffelospongia Rigby \& Collins, 2004, described as having an Eiffelia-like skeleton with apparent longitudinal monaxons that converge to form a basal tuft. Re-examination of the specimens, however, has shown that the convergent monaxons are a fringe of marginalia, and the sponge also possessed a few robust monaxon basalia (Fig. 4A). It is also unclear whether the apparent monaxons in Eiffelospongia are in fact present, as many of them are elongated vertical rays of hexaradiate or triradiate wall spicules (Fig. 4B). Variable numbers of rays in the wall spicules, as in Heteractenigma, are known in a number of heteractinid taxa, including the Cambrian Jawonya and Wagima (Kruse 1987), but the mode is typically hexaradial symmetry, with the aberrant spicules possessing additional rays. Few other heteractinids possessed spicules with a systematically lower ray number, although Botting \& Butterfield (2005) showed that Eiffelia globosa possessed a combination of hexaradiate with hexactine spicules (but no pentaradiates). Intriguingly, Blumenbachium Koenig, 1820 (cited by Finks \& Rigby 2004b) appears to have possessed dominantly stauract spicules, with some triradiate and pentaradiate spicules also present; however, the genus is very poorly known. Overall, although the Heteractinida apparently settled on dominantly hexaradiate spicules, early examples included a range of spicule symmetries. However, as the apparent monaxons of Eiffelospongia (Rigby \& Collins 2004) appear instead to be at least partly elongated rays, as evolved independently in Ensiferites (Reimann 1945), there is no previous demonstrable occurrence of monaxons in the body wall of a heteractinid.

Heteractenigma possessed variable-symmetry multirayed spicules, including pentaradiates that closely resembled those of Petaloptyon. It also had obvious monaxons, in the form of robust longitudinal oxeas in the body wall together with secondary, sub-transverse and very fine monaxons that formed localised strands. This combination of robust longitudinal monaxons with finer transverse monaxons, in a tall elongate body, is elsewhere seen only in the Leptomitidae, best exemplified by Leptomitus Walcott, 1920. Other similarities to Leptomitus include the oscular margin, which is defined by an almost identical fringe of projecting monaxons (in Heteractenigma in addition to elongated hexactine rays), and the radial reticulate skeletal organization at the base (Fig. 4E). If the monaxon spicule complement were studied in isolation, the structure would be very similar to that of a leptomitid.

Although protomonaxonids are often regarded as basal demosponges (Finks \& Rigby 2004b), other authors have argued that at least some show hexactinellid-like features (Debrenne \& Reitner 2001, Botting 2003). Early Cambrian protomonaxonids include taxa with hexactine-based spicules, indicating derivation from a different group of sponges. Steiner et al. (1993) described Hyalosinica as a probable hexactinellid root tuft, based on the presence of associated hexactines, but despite these, Rigby \& Hou (1995) suggested a leptomitid affinity instead. New material from the Hetang Biota (e.g. Fig. 4C) confirms that that the hexactines form a genuine component of the skeleton in these sponges. The spicules in the new material (several species under description by JPB and others) are generally very small hexactines with reduced, stubby rays (sometimes of variable number and orientation), organized in an irregular array.

The combination of leptomitid-like and primitive heteractinid-like aspects of the skeleton in Heteractenigma suggests a phylogenetic position near the base of the Leptomitidae, but derived from hexactine-bearing heteractinids. This suggests that small-spiculed heteractinids formed part of the stem lineage of sponges, giving rise to the more conservative eiffeliid and later heteractinids on one branch, the reticulosans and stem hexactinellids on another, and a third branch leading to protomonaxonids. The combination of 

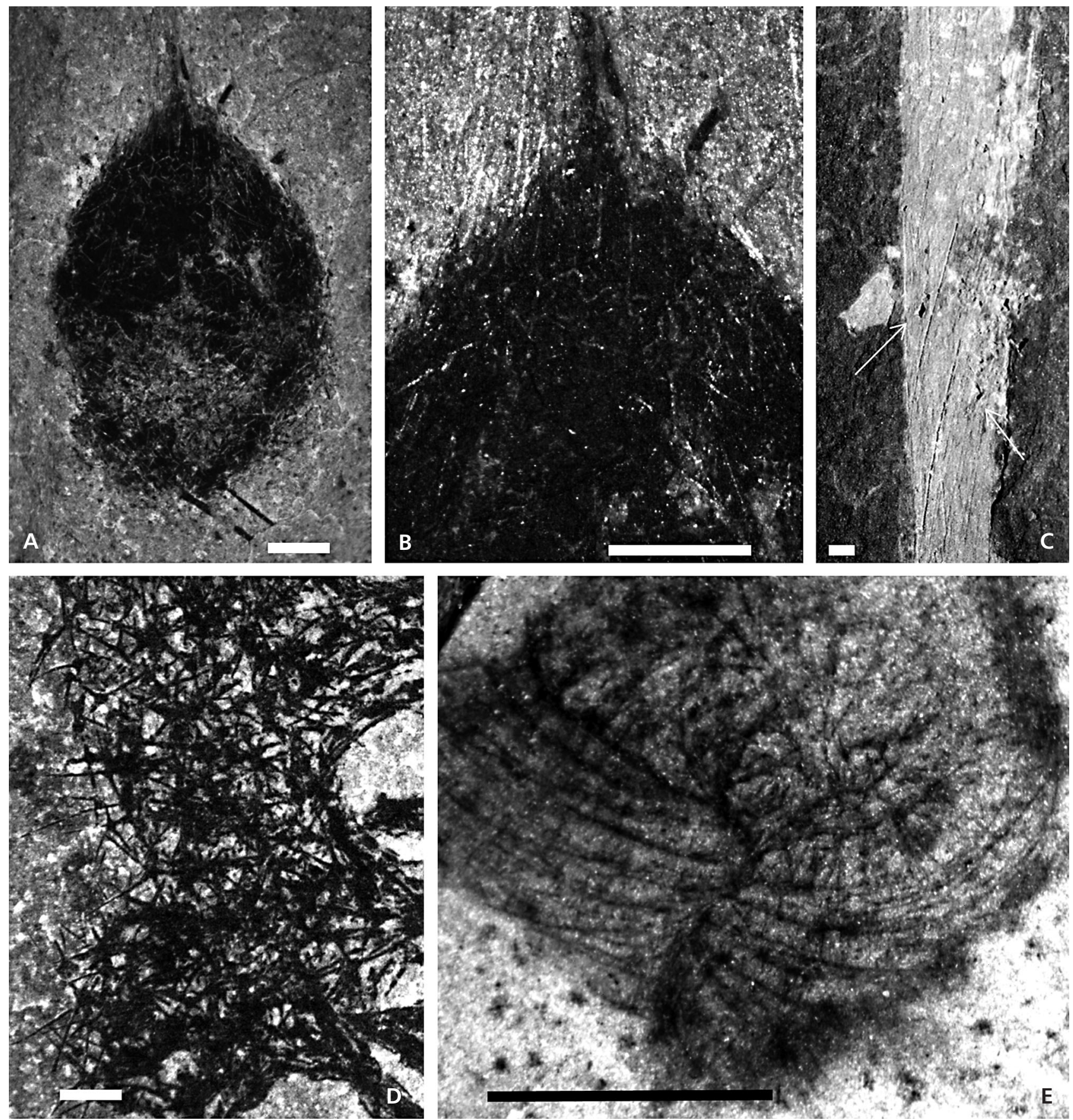

Figure 4. Cambrian sponges with superficially similar or potentially homologous features to those of Heteractenigma gen. nov. $\bullet$ A, B - Eiffelospongia hirsuta (ROM44288) from the Burgess Shale, in corrected orientation ( $c f$. Rigby \& Collins 2004), with at least some of the apical 'monaxons' formed by extended rays of dominantly hexaradiate spicules. • C - Hyalosinica? sp. (NIGP154828) from the Hetang Biota (see Xiao et al. 2005; Botting et al. 2012, in press), undescribed specimen showing thin wall of helically-arranged monaxons combined with short-rayed hexactines (examples arrowed). - D - Petaloptyon danei, detail of ROM53542 showing spicule morphology similar to that of Heteractenigma gen. nov. (compare Fig. 3B). - E - ROM53558 Leptomitus lineatus, basal region showing linear skeletal radiation centre. Scale bars: $1 \mathrm{~mm}$.

features characteristic of all three of the main extant classes (assuming that protomonaxonids are stem-group demosponges, which may not be true) suggests a nearpolychotomy for their origins. Such close separation of the three lineages would help to explain the failure of molecu- lar phylogenies to clearly resolve sponge class-level relationships (e.g. Phillippe et al. 2009, Sperling et al. 2010).

Finally, the potentially important implications of Heteractenigma show that early sponges with unusual suites of characters can be the most informative taxa. These 
unexpected character combinations are critical to reconstructing early sponge evolution, and enigmatic sponges should be re-examined in light of the emerging framework of sponge stem-group taxa. The primary conclusion based on the new species is that there are large areas of early sponge phylogeny of which we are currently ignorant; occasional specimens such as this can shed significant new light onto the nature of the common ancestors of the extant classes.

\section{Acknowledgements}

Thanks to Jean-Bernard Caron and Peter Fenton for access to specimens and photomicroscope in the Royal Ontario Museum (ROM), and to Lucy Muir for helpful discussion. Radek Vodrážka and Andzrej Pisera improved the manuscript through their constructive reviews. JPB's research is supported by the CAS Project-Oriented Hundred Talents Programme to Jih-Pai Lin (grant No. KZCX2-YW-BR-23), the National Science Foundation of China Research Fellowship for International Young Scientists (grant No. 41150110152) and the ROM visit to examine Burgess Shale material was partly funded by the Chinese Academy of Sciences Fellowships for Young International Scientists (grant No. 2010Y2ZA03).

\section{References}

Bengtson, S. \& Hou, X.-G. 2001. The integument of Cambrian chancelloriids. Acta Palaeontologica Polonica 46, 1-22.

Bengtson, S. \& Vinther, J. 2006. The role of Eiffelia in early sponge evolution. Geological Society of America Abstracts with Programs 38, 304.

Botting, J.P. 2003. Cyathophycus and the origin of demosponges. Lethaia 36, 335-344. DOI $10.1080 / 00241160310006385$

BotTing, J.P. 2004. A revision of the hexactinellid sponge Amphispongia oblonga Salter, 1861: not a dasycladacean alga. Scottish Journal of Geology 40, 115-118.

DOI 10.1144/sjg40020115

Botting, J.P. \& Butterfield, N.J. 2005. Reconstructing early sponge relationships by using the Burgess Shale fossil Eiffelia globosa Walcott. Proceedings of the National Academy of Sciences of the United States of America 102, 1554-1559. DOI 10.1073/pnas.0405867102

BotTing, J.P., Muir, L.A., Li, X.-F. \& Lin, J.-P. in press. A problematic, probably chemosymbiotic hexactinellid sponge from the early Cambrian of South China. Acta Palaeontologica Polonica.

Botting, J.P., Muir, L.A., XiaO, S., Li, X.-F. \& Lin, J.-P. 2012. Evidence for spicule homology in calcareous and siliceous sponges: biminerallic spicules in Lenica sp. (Porifera; ?Protomonaxonida) of early Cambrian age (535-520 Ma) from South China. Lethaia 45, 463-375.

DOI 10.1111/j.1502-3931.2012.00308.x

Botting, J.P. \& Rhebergen, F.A. 2011. A remarkable new Mid- dle Sandbian (Ordovician) hexactinellid sponge in Baltic erratics. Scripta Geologica 143, 1-14.

Chen, J., Hou, X. \& Lu, H. 1989. Lower Cambrian leptomitids (Demospongea), Chengjiang, Yunnan. Acta Palaeontologica Sinica 28, 17-31.

Debrenne, F. \& Reitner, J. 2001. Sponges, Cnidarians, and Ctenophores, 301-325. In Zhuravlev, A.Y. \& Riding, R. (eds) The Ecology of the Cambrian Radiation. Columbia University Press, New York.

De Laubenfels, M.W. 1955. Porifera, E21-Ell2. In Moore, R.C. (ed.) Treatise on Invertebrate Paleontology, Part E, Archaeocyatha and Porifera. University of Kansas \& Geological Society of America, Lawrence.

Finks, R.M., ReID, R.E.H. \& RigBy, J.K. (eds) 2003. Treatise on Invertebrate Paleontology, Part E (revised), Volume 2. 349 pp. Geological Society of America \& University of Kansas Press, Lawrence.

Finks, R.M. \& Rigby, J.K. 2004a. Paleozoic Demosponges, 9-171. In Finks, R.M., ReID, R.E.H. \& Rigby, J.K. (eds) Treatise on Invertebrate Paleontology, Part E (revised), Volume 3. Geological Society of America \& University of Kansas Press, Lawrence.

FinKs, R.M. \& Rigby, J.K. 2004b. Heteractinida, 557-583. In Finks, R.M., ReID, R.E.H. \& Rigby, J.K. (eds) Treatise on Invertebrate Paleontology, Part E (revised), Volume 3. Geological Society of America \& University of Kansas Press, Lawrence.

Finks, R.M. \& RigBY, J.K. 2004c. Hypercalcified sponges, 587-764. In FinKs, R.M., ReID, R.E.H. \& RigBY, J.K. (eds) Treatise on Invertebrate Paleontology, Part E (revised), Volume 3. Geological Society of America \& University of Kansas Press, Lawrence.

García-Bellido Capdevilla, D. 2003. The demosponge Leptomitus cf. L. lineatus, first occurrence from the Middle Cambrian of Spain (Murero Formation, Western Iberian Chain). Geologica Acta 1, 113-119.

Grabau, A.W. 1923-1924. Stratigraphy of China, Part 1, Paleozoic and Older. 528 pp. Geological Survey, Ministry of Agriculture and Commerce, Peking.

Grant, R.E. 1836. Animal Kingdom, 107-118. In TodD, R.B. (ed.) The Cyclopedia of Anatomy and Physiology, vol. 1 . Sherwood, Gilbert \& Piper, London.

Harvey, T.H.P. 2010. Carbonaceous preservation of Cambrian hexactinellid sponge spicules. Biology Letters 6, 834-837. DOI 10.1098/rsbl.2010.0377

KoENIG, C.D.E. 1820. Icones fossilium sectilis, centuria prima. 4 pp., 19 pl. C. Koenig, London.

Kruse, P.D. 1987. Further Australian Cambrian sphinctozoans. Geological Magazine 124, 543-553. DOI 10.1017/S0016756800017374

Mehl, D. \& ReITNER, J. 1996. Observations on Astraeospongium meniscum (Roemer, 1848), from the Silurian of western Tennessee: constructional morphology and palaeobiology of the Astraeospongiidae (Calcarea, Heteractinellidae). Berliner geowissenschaftliche Abhandlungen 18, 243-255.

Philippe, H., Derelle, R., Lopez, P., Pick, K., Borchiellini, C., Boury-Esnault, N., Vacelet, J., Renard, E., Houliston, E., Quéinnec, E., da Silva, C., Wincker, P., Le Guyader, H., Leys, S., Jackson, D.J., Schreiber, F., ErPenbeck, D., 
Morganstern, B., Wörheide, G. \& Manuel, M. 2009. Phylogenomics revives traditional views on deep animal relationships. Current Biology 19, 1-7.

DOI 10.1016/j.cub.2009.02.052

RAYMOND, P.E. 1931. Notes on invertebrate fossils, with descriptions of new species. Bulletin of the Museum of Comparative Zoology at Harvard College 55, 165-213.

ReID, R.E.H. 1958. The Upper Cretaceous Hexactinellida. Monograph of the Palaeontographical Society, London 111, i-xlvi.

REID, R.E.H. 1967. Hyalostelia Zittel and the Heteractinellida. Geological Magazine 104, 398-399. DOI 10.1017/S0016756800049001

Reimann, I.G. 1945. New Middle Devonian octactinellids. Paleontological Contributions, Buffalo Society of Natural Science Bulletin 19, 16-21.

RietsChel, S. 1968. Die Octactinellida und ihnen verwandte paliozoische Kalkschwimme (Porifera, Calcarea). Paläontologische Zeitschrift 42, 13-32.

RigBY, J.K. 1986. Sponges of the Burgess Shale (Middle Cambrian) British Columbia. Palaeontographica Canadiana Monograph 2, 1-105.

RigBy, J.K. \& Collins, D. 2004. Sponges of the Middle Cambrian Burgess and Stephen Shale Formations, British Columbia. Royal Ontario Museum Contributions in Science 1, 1-164.

RigbY, J.K. \& Hou, X.-G. 1995. Lower Cambrian demosponges and hexactinellid sponges from Yunnan, China. Journal of $P a$ leontology 69, 1009-1019.

RigBy, J.K. \& NiteCKI, M.H. 1975. An unusually well preserved heteractinid sponge from the Pennsylvanian of Illinois and a possible classification and evolutionary scheme for the Heteractinida. Journal of Palaeontology 49, 329-339.

Rigby, J.K., Senowbari-Daryan, B. \& Hamedani, A. 2005. First reported occurrence of wewokellid sponges (Calcarea, Heteractinida) from the Permian of central Iran. Facies 51, 516-521. DOI 10.1007/s10347-005-0072-7

Rong, J.Y., Zhan, R.B., Xu, H.G., HuAnG, B. \& Yu, G.H. 2010. Expansion of the Cathaysian Oldland through the Ordovician-Silurian transition: Emerging evidence and possible dynamics. Science China (Earth Sciences) 53(1), 1-17. DOI 10.1007/s11430-010-0005-3
Sperling, E.A., Robinson, J.M., Pisani, D. \& Peterson, K.J. 2010. Where's the glass? Biomarkers, molecular clocks, and microRNAs predict a 200-Myr missing Precambrian fossil record of siliceous sponge spicules. Geobiology 8, 24-36. DOI 10.1111/j.1472-4669.2009.00225.x

Steiner, M., Mehl, D., Reitner, J. \& Erdtmann, B.-D. 1993. Oldest entirely preserved sponges and other fossils from the Lowermost Cambrian and a new facies reconstruction of the Yangtze platform (China). Berliner geowissenschaftliche Abhandlungen 9, 293-329.

WalcotT, C.D. 1920. Middle Cambrian Spongiae. Cambrian geology and paleontology IV. Smithsonian Miscellaneous Collections 67, 261-364.

Wu, W., Yang, A.H., Janussen, D., Steiner, M. \& Zhu, M.Y. 2005. Hexactinellid sponges from the Early Cambrian black shale of South Anhui, China. Journal of Paleontology 79, 1043-1051.

DOI 10.1666/0022-3360(2005)079[1043:HSFTEC]2.0.CO;2

Xiao, S., Hu, J., Yuan, X., Parsley, R.L. \& Cao, R. 2005. Articulated sponges from the Lower Cambrian Hetang Formation in southern Anhui, South China: their age and implications for the early evolution of sponges. Palaeogeography, Palaeoclimatology, Palaeoecology 220, 89-117.

DOI 10.1016/j.palaeo.2002.02.001

Yu, G.H. (ed.) 1996. Stratigraphy (Lithologic) of Zhejiang Province. Multiple Classification and Correlation of the Stratigraphy of China, Stratigraphy (Lithologic) of Zhejiang Province. 236 pp. China University of Geosciences Press, Beijing.

Zhang, Y.D., Chen, X., Goldman, D., Zhang, J., Cheng, J.F. \& SoNG, Y.Y. 2010. Diversity and paleobiogeographic distribution patterns of Early and Middle Ordovician graptolites in distinct depositional environments of South China. Science China (Earth Sciences) 40(9), 1164-1180.

Zhang, Y.D., Chen, X., Yu, G.H., Goldman, D. \& Liu, X. 2007. Ordovician and Silurian Rocks of Northwest Zhejiang and Northeast Jiangxi Provinces, SE China. 189 pp. University of Science and Technology of China Press, Hefei.

Zhang, Y.D., Zhang, J., Wang, J.G., Song, Y.Y., Wang, L.W., Yu, G.H. \& LI, K.Q. in press. Preliminary report on the biostratigraphy of the Ordovician in Liujia section, Tonglu, Zhejiang Province. Journal of Stratigraphy. 